\title{
CARACTERÍSTICAS DAS LESÕES CORPORAIS DECORRENTES DE VIOLÊNCIA FÍSICA EM CRIANÇAS E ADOLESCENTES REGISTRADO NO INSTITUTO MÉDICO LEGAL (IML) EM FEIRA DE SANTANA - BAHIA, NO ANO DE 2014
}

\section{Hosannah Leite Filho; Maria Conceição Oliveira Costa²; Mona Lisa Cordeiro Asselta da Silva $^{3}$ e Daniela Pereira Portugal Souza ${ }^{4}$}

1. Bolsista PIBIC/FAPESB, Graduando em Medicina, Universidade Estadual de Feira de Santana, e-mail: hosannah@outlook.com

2. Orientadora, Departamento de Saúde, Universidade Estadual de Feira de Santana, e-mail: oliveiramco69@ gmail.com

3. Participante do projeto e Mestre em Saúde Coletiva, Departamento de Saúde, Universidade Estadual de Feira de Santana, e-mail: mona.cordeiro@hotmail.com

4. Participante do projeto, Departamento de Saúde, Universidade Estadual de Feira de Santana, e-mail: dannieport@gmail.com

PALAVRAS-CHAVE: Violência, Criança; Adolescente.

\section{INTRODUÇÃO}

A violência de uma forma geral em crianças e adolescentes é conceituada como toda ação ou omissão, que tenha como resultado qualquer forma de dor, provocado por pessoa com maturidade mais adiantada (PFEIFFER et al., 2011). É um fenômeno que acontece independente de raça, classe social ou cultura (GARBIN et al., 2011). A localização da lesão pode ser um importante indício de ocorrência de violência física.

O segmento corporal mais atingido em casos de violência é a face, justamente por ser a face, a parte do corpo mais exposta e menos protegida. Na maioria das vezes, o trauma facial está associado a fraturas dentárias, contusões, equimoses, abrasões e lacerações, acometendo principalmente as pessoas jovens, pelo fato de serem mais ativas (GODOI et al., 2013; FRANÇA, 2008). Diante do exposto, o presente estudo visou fornecer um maior conhecimento acerca da temática, compreendendo as características das lesões corporais em crianças e adolescente na cidade de Feira de Santana, buscando mimetizar qualquer tipo de violência física nesse público alvo. Sinalizar para a comunidade acadêmica, sociedade local, instancias de proteção e outros órgãos envolvidos na defesa de direitos da criança e do adolescente, a forma e o tipo de lesão física, registrada no IML, a fim de proporcionar a reflexão e discussão de possíveis soluções para a diminuição dos casos registrados. Compreender a violência e coibi-la é de grande importância para a sociedade e para a saúde pública brasileira.

O objetivo desse estudo foi analisar as características das lesões corporais, decorrentes de violência física, em crianças e adolescentes em Feira de Santana-Bahia, registrados no IML no ano de 2014.

\section{MATERIAL E MÉTODOS OU METODOLOGIA (ou equivalente)}

Estudo epidemiológico exploratório do tipo transversal sobre características das lesões corporais em crianças ( $\leq 11$ anos) e adolescentes (12-18 anos) vítimas de violência, submetidas ao exame de lesão corporal no IML de Feira de Santana, no período de 01 de janeiro de 2014 a 31 de dezembro de 2014. Na pesquisa foi utilizada fonte de dados secundários coletados através dos laudos periciais arquivados nesta instituição. Os dados foram processados eletronicamente através do programa estatístico Social Package for the Social Sciences - SPSS for Windows, versão 17.0. O presente projeto de pesquisa foi cadastrado na Plataforma Brasil e aprovado pelo Comitê de Ética em Pesquisa com Seres Humanos (CEP) da Universidade Estadual de Feira de Santana/UEFS (CAAE 46251015.2.0000.0053), atendendo as normas da Resolução 466/12, do Conselho Nacional de 
Saúde, de 12 de dezembro de 2012, publicada em 13 de junho de 2013, no Diário Oficial da União, que revoga a Resolução nº 196/96, de 10 de outubro de 1996.

\section{RESULTADOS E/OU DISCUSSÃO}

Foram notificados em 2014 no IML, 411 crianças e adolescentes vítimas de violência física. No que tange o perfil das vítimas, ocorreram em ambos os sexos, sendo o sexo masculino mais prevalente. A faixa da adolescência (12-18 anos), no quesito faixa etária, foi o mais evidente $(83,4 \%)$, sendo que as proporções de lesões em cabeça e pescoço foram similares, em torno de 52\%. Resultados similares foram encontrados em Souza et al. (2014) e de Guimarães e Vilella (2011) os quais mostraram maior prevalência de vítimas adolescentes, $55,6 \%$ e $62,7 \%$.

Tendo maior registro, Feira de Santana a cidade mais significante (70,3\%). O município se destaca pelo grande fluxo migratório marcado pela sua localização geográfica, uma vez que é cortado por três Rodovias Federais e cinco Rodovias Estaduais, sendo considerado o maior entroncamento rodoviário do Norte e Nordeste do Brasil.

A cabeça $35,7 \%$, membros superiores $28,0 \%$, membros inferiores 16,9 foram os segmentos corpóreos mais relacionado com o tipo de violência física, estudo similar de Martins e Andrade (2005) e de Garbin et al. (2006), foi relatado que 34,9\% e 30,0\% das vítimas foram atingidas em região de cabeça e pescoço, seguido dos membros superiores, $24,3 \%$ e $24,4 \%$, corroborando com o presente estudo. As agressões em região de cabeça e pescoço são mais frequentes, possivelmente, por serem áreas anatômicas de maior proeminência ou pela posição do agressor em relação à vítima, também vinculado a possíveis agressões devido a choros ou sua defesa verbal. Nos membros superiores, geralmente, ocorrem às chamadas "lesões de defesa" que são aquelas produzidas no momento de movimentação da vítima, para se defender do agressor.

A lesão contusa foi a mais prevalente, $79,8 \%$, dentre as quais $44,0 \%$ destas lesões foram do tipo escoriações, seguida de equimose 25,3\%, Edema traumático 21,4\%. As lesões contusas podem ser fechadas ou abertas.

A maior parte dos adolescentes apresentaram lesões corporais decorrentes da violência física, 83,2\%, no entanto, não houve diferença entre os grupos etários, quando estudada a região de cabeça e pescoço. Tão quanto a violência contra a mulher, as crianças são mais vitimadas na região de cabeça e pescoço, isto por que, é mais próxima ao nível da mão do agressor e de maior visibilidade (Minayo, 1994). Próximos foram os resultados quanto ao sexo, sendo o masculino mais incidente $54,3 \%$.

Os agressores que provocaram lesões corporais em crianças e adolescentes registradas no IML de Feira de Santana, em sua maior parte, não eram membros da família da vítima $72,8 \%$, onde $50,9 \%$ atingiram a vítima na região de cabeça e pescoço. As lesões provocadas por agressores membros da família atingiram a região cabeça e pescoço da vítima em $56,1 \%$ dos casos.

Quanto ao tipo ao instrumento utilizado, o instrumento contundente foi o mais prevalente, $83,5 \%$. Quando associada a região da cabeça e pescoço, o tipo de instrumento mais comum utilizado e significante foi o instrumento cortante, perfurante, perfurocortante, perfurocontudente e cortocontudente, $84,9 \%$.

Tabela 1- Características sociodemográficas de crianças e adolescentes vítimas de violência física submetidas a exame de lesão corporal no IML de Feira de Santana-BA, 2014

\begin{tabular}{lcc}
\hline CARACTERÍSTICAS SOCIODEMOGRÁFICA DA VÍTIMA & $\mathrm{n}$ & $\%$ \\
\hline SEXO (N=411) & 218 & 53,0 \\
Masculino & 193 & 47,0
\end{tabular}




$\begin{array}{lcc}\text { FAIXA-ETÁRIA }(\mathrm{N}=411) & & \\ 0-6 & 24 & 5,8 \\ 7-11 & 44 & 34,5 \\ 12-15 & 142 & 48,9 \\ 16-18 & 201 & 7,2 \\ \text { COR DA PELE }(\mathrm{N}=401) & 29 & 91,3 \\ \text { Melanoderma } & 366 & 1,5 \\ \text { Faioderma } & 6 & 2,9 \\ \text { Leucoderma } & & 3,8 \\ \text { ESCOLARIDADE (N=314) } & 9 & 69,4 \\ \text { Não alfabetizado } & 12 & 5,4 \\ \text { Alfabetizado } & 218 & 16,2 \\ \text { Ensino Fundamental Incompleto } & 17 & 2,3 \\ \text { Ensino Fundamental Completo } & 51 & \\ \text { Ensino Médio Incompleto } & 7 & 70,3 \\ \text { Ensino Médio Completo } & & 29,7 \\ \text { NATURALIDADE (N= 404) } & & \\ \text { Feira de Santana } & 284 & \\ \text { *Outros } & 120 & \end{array}$

Tabela 2- Características das lesões em crianças e adolescentes vítimas de violência física periciadas no IML de Feira de Santana-BA, 2014

\begin{tabular}{|c|c|c|c|c|c|}
\hline \multirow[t]{2}{*}{ CARACTERÍSTICAS DA VÍTIMA } & \multirow[t]{2}{*}{$\mathrm{P}$} & \multirow[t]{2}{*}{$\%$} & \multicolumn{2}{|c|}{$\begin{array}{l}\text { TRAUMA EM CABEÇA E } \\
\text { PESCOCO }\end{array}$} & \multirow[t]{2}{*}{$\mathrm{p}$} \\
\hline & & & $\mathrm{N}$ & $\%$ & \\
\hline \multicolumn{6}{|l|}{ FAIXA-ETÁRIA (N=327) } \\
\hline $0-11$ & 55 & 16,8 & 29 & 52,7 & \multirow{3}{*}{0,9} \\
\hline $12-18$ & 272 & 83,2 & 142 & 52,2 & \\
\hline \multicolumn{5}{|l|}{ SEXO $(N=327)$} & \\
\hline Masculino & 162 & 49,5 & 88 & 54,3 & \multirow[b]{2}{*}{0,5} \\
\hline Feminino & 165 & 50,5 & 83 & 44,9 & \\
\hline \multicolumn{6}{|l|}{ CARACTERÍSTICAS DA AGRESSÃO } \\
\hline \multicolumn{6}{|c|}{ AGRESSOR $(\mathrm{N}=151)$} \\
\hline Familiar & 41 & 27,2 & 23 & 56,1 & \multirow{3}{*}{0,6} \\
\hline Não familiar & 110 & 72,8 & 56 & 50,9 & \\
\hline \multicolumn{5}{|l|}{ LOCAL DA AGRESSÃO (N=172) } & \\
\hline Domicílio & 61 & 35,5 & 33 & 54,1 & \multirow{2}{*}{0,3} \\
\hline Extra Domicílio & 111 & 64,5 & 51 & 45,9 & \\
\hline \multicolumn{6}{|l|}{ CARACTERÍSTICAS DA LESÃO } \\
\hline \multicolumn{6}{|l|}{ NÚMERO DE LESÕES (N=323) } \\
\hline 1 & 144 & 44,6 & 80 & 55,6 & \multirow{4}{*}{0,3} \\
\hline$\geq 2$ & 179 & 55,4 & 89 & 49,7 & \\
\hline INSTRUMENTO UTILIZADO $(\mathrm{N}=$ & & & & & \\
\hline Contundente & 268 & 83,5 & 124 & 46,3 & \\
\hline Outros & 53 & 16,5 & 45 & 84,9 & $<0,001$ \\
\hline
\end{tabular}

Tabela 3 - Características das lesões em crianças e adolescentes vítimas de violência física periciadas no IML de Feira de Santana-BA, 2014

\begin{tabular}{lcc}
\hline CARACTERÍSTICAS DAS LESÕES & $\mathrm{n}$ & $\%$ \\
\hline Número de lesões (N= & & \\
332 ) & 147 & 44,3 \\
1 & 185 & 55,7 \\
$\geq 2$ & & \\
REGIÃO DO CORPO AFETADO & & \\
N=479) & 171 & 35,7 \\
Cabeça & 19 & 4,0 \\
Pescoço & 74 & 15,4 \\
Tronco & 134 & 28,0 \\
Membros superiores & 81 & 16,9 \\
Membros inferiores & & \\
TIPO DE LESÃO (N=347) & 277 & 79,8 \\
Contusa & 26 & 7,5 \\
Cortocontusa & 18 & 5,2 \\
Perfurocontusa & 9 & 2,6 \\
Incisa & 9 &
\end{tabular}




\begin{tabular}{lcc} 
Perfuroincisa & 9 & 2,6 \\
*Outras & 8 & 2,3 \\
TIPO DE LESÕES CONTUSAS (N= 384) & & \\
Escoriação & 169 & 44,0 \\
Equimose & 97 & 25,3 \\
Edema traumático & 82 & 21,4 \\
Hematoma & 30 & 7,8 \\
$* *$ Outros & 6 & 1,5 \\
\hline
\end{tabular}

*Outros: queimadura (3); cicatriz (4); e punctória (1).

**Outros: bossas linfáticas e sanguines (4); e rubefação (2).

\section{CONSIDERAÇÕES FINAIS}

Cotidianamente crianças e adolescentes se tornam vítimas de algum tipo de violência. Presente em nossa sociedade, a violência doméstica contra crianças e adolescentes configurase como um fenômeno social e histórico, que envolve aspectos psicossociais e um caráter dinâmico de interação familiar, de modelo social e cultural, que se estabelece na relação vítima e agressor.

O presente estudo evidenciou a faixa etária da adolescência (12-18 anos) a mais prevalente das vítimas, sendo o sexo masculino levemente mais vitimizados (53\%) do que o sexo feminino. Quando associada ao local da lesão, a cabeça e pescoço foi o local mais acometido $39,7 \%$.

Coibir qualquer tipo de violência para este público estudado é uma tarefa árdua e complexa que deverá envolver todas as esferas sociais como a educação, segurança pública, saúde pública e comunidade. Partilhar a informação através da educação é primordial.

\section{REFERÊNCIAS}

FRANÇA, G. V. Medicina legal, 8 ${ }^{a}$. ed., Rio de Janeiro: Guanabara Koogan, 2008.

GARBIN, C. A. S.; ROVIDA, T. A. S.; JOAQUIM, R. C.; PAULA, A. P.; QUEIROZ, A. P. D. G. Violência denunciada: ocorrências de maus tratos contra crianças e adolescentes registradas em uma unidade policial. Revista Brasileira Enfermagem, Brasília, v. 64, n. 4, p. 665-670, jul/ago, 2011.

GODOI, M. S.; BASUALDO, A.; OLIVEIRA, K. C. Índice de fraturas faciais no Hospital São Vicente de Paulo em Passo Fundo RS: estudo retrospectivo de dez anos. J Oral Invest, v.2, n.2, p. 14-19, 2013.

GUIMARÃES, J. A. T. L.; VILELLA, W. V. Características da violência física e sexual contra crianças e adolescentes atendidos no IML de Maceió, Alagoas, Brasil. Caderno de Saúde Pública, v. 27, n.8, p. 1617-1647, 2011.

MARTINS, C. B. G.; ANDRADE, S. M. Causas externas entre menores de 15 anos em cidade do Sul do Brasil: atendimentos em pronto socorro, internações e óbitos. Revista Brasileira de Epidemiologia. v. 8, n. 2, p. 194-204, 2005.

Minayo MCS. A violência social sob perspectiva da saúde pública. Cad Saúde Pública 1994; 10 Suppl 1:7-18.

PFEIFFER, L.; ROSÁRIO, N. A.; CAT, M. N. L. Violência contra crianças e adolescentes proposta de classificação dos níveis de gravidade. Revista Paulista Pediatria, São Paulo, v.29, n.4, p. 477-482, 2011.

SOUZA, C. S.; COSTA, M. C. O.; ASSIS, S. G.; MUSSE, J. O.; SOBRINHO, C. N.; AMARAL, M. T. R. Sistema de Vigilância de Violências e Acidentes/VIVA e a notificação da violência infanto-juvenil, no Sistema Único de Saúde/SUS de Feira de Santana-Bahia, Brasil. Ciência \& Saúde Coletiva, n. 19, v.3, p. 773-784, 2014. 